\title{
Near-infrared shielding performance of tungsten-doped tin dioxide nanoparticles
}

Zhen Lia ${ }^{1}$, Yajun Chen ${ }^{\text {1 }}$, Shuangjiang $\mathrm{Li}^{\mathrm{a}}$, Yunfei Zhi ${ }^{\mathrm{a}}{ }^{*}$, Yonghao Nia, bei Tao ${ }^{\mathrm{c}}$, Shaoyun Shan ${ }^{\mathrm{a},}{ }^{* *}$

${ }^{a}$ Faculty of Chemical Engineering, Kunming University of Science and Technology, Kunming, 650500, China

${ }^{\mathrm{b}}$ Limerick Pulp and Paper Centre, University of New Brunswick, Fredericton, E3B5A3, Canada

${ }^{c}$ College of Resource and Environment Science, Anqing Normal University, Anqing, 246133, China

${ }^{1}$ These authors contributed equally to this work.

* and ${ }^{* *}$ Corresponding author.

E-mail: zyf891123@163.com;

** E-mail: shansy411 @163.com; 
The SEM of nano-WTO powder with different calcination temperature and hydrothermal temperature is illustrated in Figure $\mathrm{S} 1$ a- i. The crystal size of $\mathrm{SnO}_{2}$ at different calcination temperature and hydrothermal temperature is about $10 \sim 30 \mathrm{~nm}$.

(a)

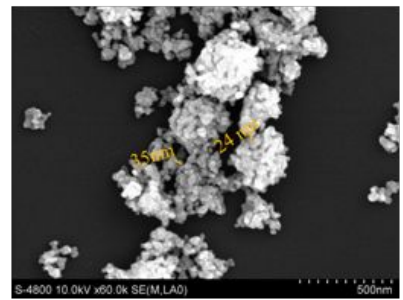

(d)

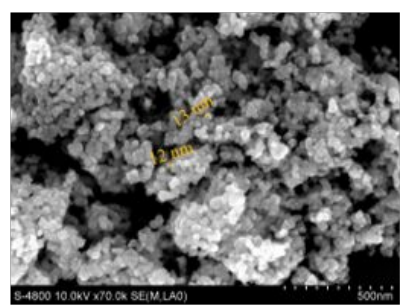

(g)

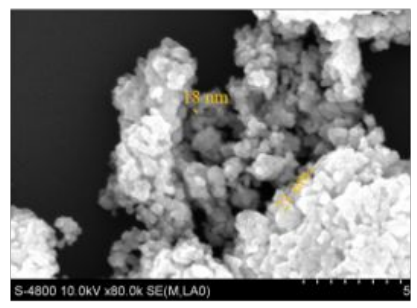

(b)

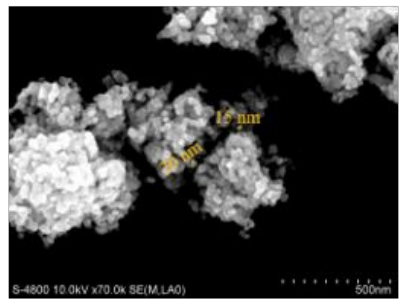

(e)

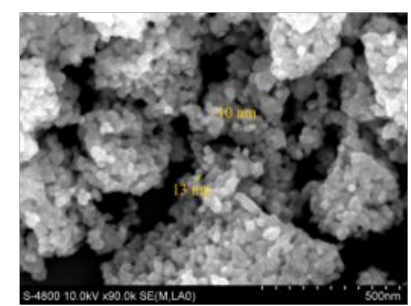

(h)

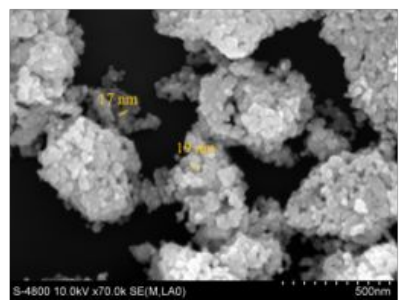

(c)

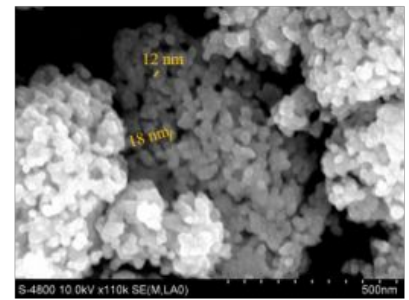

(f)

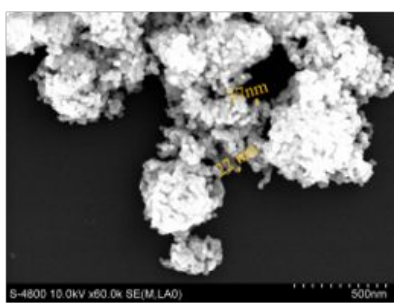

(i)

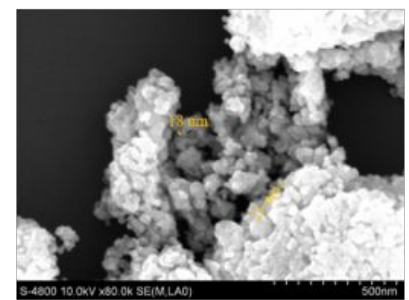

Figure S1 SEM image of nano-WTO powder with different calcination

temperature:(a) $600{ }^{\circ} \mathrm{C}$, (b) $700{ }^{\circ} \mathrm{C}$, (c) $800{ }^{\circ} \mathrm{C}$, (d) $900{ }^{\circ} \mathrm{C}$, (e) $1000{ }^{\circ} \mathrm{C}$; with different hydrothermal temperature: (f) $160^{\circ} \mathrm{C}$, (g) $170{ }^{\circ} \mathrm{C}$, (d) $180{ }^{\circ} \mathrm{C}$, (h) $190^{\circ} \mathrm{C}$, (i) $200^{\circ} \mathrm{C}$. 